\title{
Influence of non-sinusoidal power supply on the performance of a single-phase capacitor induction motor
}

\author{
Omar Sharaf Al-deen Alyozbaky ${ }^{1,2}$, Mohd Zainal Abidin Ab-Kadir \\ ${ }^{1}$ Electrical Department, College of Engineering, University of Mosul, Ninava, Iraq \\ ${ }^{2}$ Centre for Electromagnetic and Lightning Protection Research (CELP), Faculty of Engineering, Universiti Putra Malaysia, Selangor, \\ Malaysia
}

\begin{abstract}
Article Info
Article history:

Received Aug 20, 2021

Revised Dec 31, 2021

Accepted Jan 17, 2022

Keywords:

Harmonics

Induction motor

Noise

Non-sinusoidal supply

Running capacitor

ABSTRACT

Harmonic is seen to be an important factor that can influence the performance of different electrical appliances. Earlier studies have regarded the nonsinusoidal power supply as the major source of the harmonic in the induction motors. In this paper, the researcher compared the results generated by a single-phase capacitor induction motor (SIM) using the sinusoidal and nonsinusoidal power supplies. The results in the study could help in comprehensively understanding the impact of the harmonic on the effective performance of the SIM machines when they were powered using a nonsinusoidal power supply. Here, the performance of the SIM when subjected to a maximum load or non-load condition were studied and determined. Furthermore, numerous experimental work was presented to validate the results of the SIM. Power analyses and spectral analysis indicated the actual difference in the overall harmonic wave distortion. It was seen that the current load increased to $89 \%$ (i.e., an increase of $11 \%$ ) when the motor working from the non-sinusoidal source. This investigation highlighted the direct impact of the non-sinusoidal power source on the properties and components of the SIM machine. The vibrations measured under varying conditions and compared the results for the 2 types of power supplies.
\end{abstract}

This is an open access article under the CC BY-SA license.

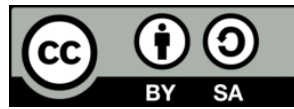

\section{Corresponding Author:}

Omar Sharaf Al-Deen Alyozbaky

Department of Electrical Engineering, Collage of Engineering, Universiti of Mosul

Ninava, Iraq

Email: O.SH.Alyozbaky@gmail.com

\section{INTRODUCTION}

Numerous countries, villages and towns utilise single-phase capacitor induction motors (SIMs) for various purposes. SIMs are used many domestic applications. They are preferred in applications that do not require a variable speed drive due to their low cost and rugged construction. SIMs are also commonly used as fans, compressors, a drive for low-power pumps and other instruments [1]. Various instruments in application homes use SIM because of its advantages, such as simple construction, convenient usage, easy transfer and low maintenance [2]-[5]. Recently, electrical power systems have presented many problems, including power outages, especially in countries suffering from long- and medium-term electricity cut-off [6], [7]. As a result, many people use another resource to supply power to their instruments and equipment. One of the most popular appliances is the inverter, which provides electricity by changing direct current (DC) to alternator current (AC) [8]-[12]. Induction motors are usually used in industries and are seen to be very sensitive to voltage harmonic waveforms. Furthermore, their efficiency and operation are significantly affected by the quality of power supplied to the machines. 
Thorough experimental investigations are crucial, for analysing the induction motor's current signature, to assess the failure prevention capacity and preventive maintenance diagnostics, in drive systems that utilize induction motors (IM). The results in [13] indicate that the recommended pulse width modulation (PWM) approaches fall short, when it comes to proportional-derivative (PD) PWM. Up to date literature in this area, documents descriptions on the diagnostic procedures for machines [14]. Also documented are the diagnostic techniques for bearings [15]. Diagnostic methods are based on several signals, such as electric current, vibration [16]-[18] and acoustic signals [5], [19], [20]. According to the experimental results, when the motor used different run capacitors in the different loads, bearing and armature faults give rise to distortions in the current wave [21]. A decrease in their efficiency would increase their losses. It was noted that when the output of these induction motors is set at a nominal value, their input power has to be increased.

Recently, several works [22]-[24] studied and analyized IM monitoring in where various stator and rotor failures, their causes and detection methods. Modern software, microprocessor, Artificial intelligence algorithms and other security and control technologies assisted diagnostic methods. Table 1 displays the faults in the induction motor.

Table 1. Induction motor faults [25]

\begin{tabular}{ccccc}
\hline Studied by & Bearing fault (\%) & Stator fault (\%) & Rotor fault (\%) & Others (\%) \\
\hline IEEE & 42 & 28 & 8 & 22 \\
EPRI & 41 & 36 & 9 & 14 \\
\hline
\end{tabular}

There are many applications can have used to convert the speed of electrical motor. One of these method change the frequency which proportion with speed [26]. The signal of the fault current considered the first step of diagnostic the fault inside the electrical motor [27], [28], vibrations [16]-[18], [29]-[32], acoustic signals [5], [19], [20], [33]-[35]. In the Figure 1, a taxonomy of the faults in the single phase induction motor is shown.

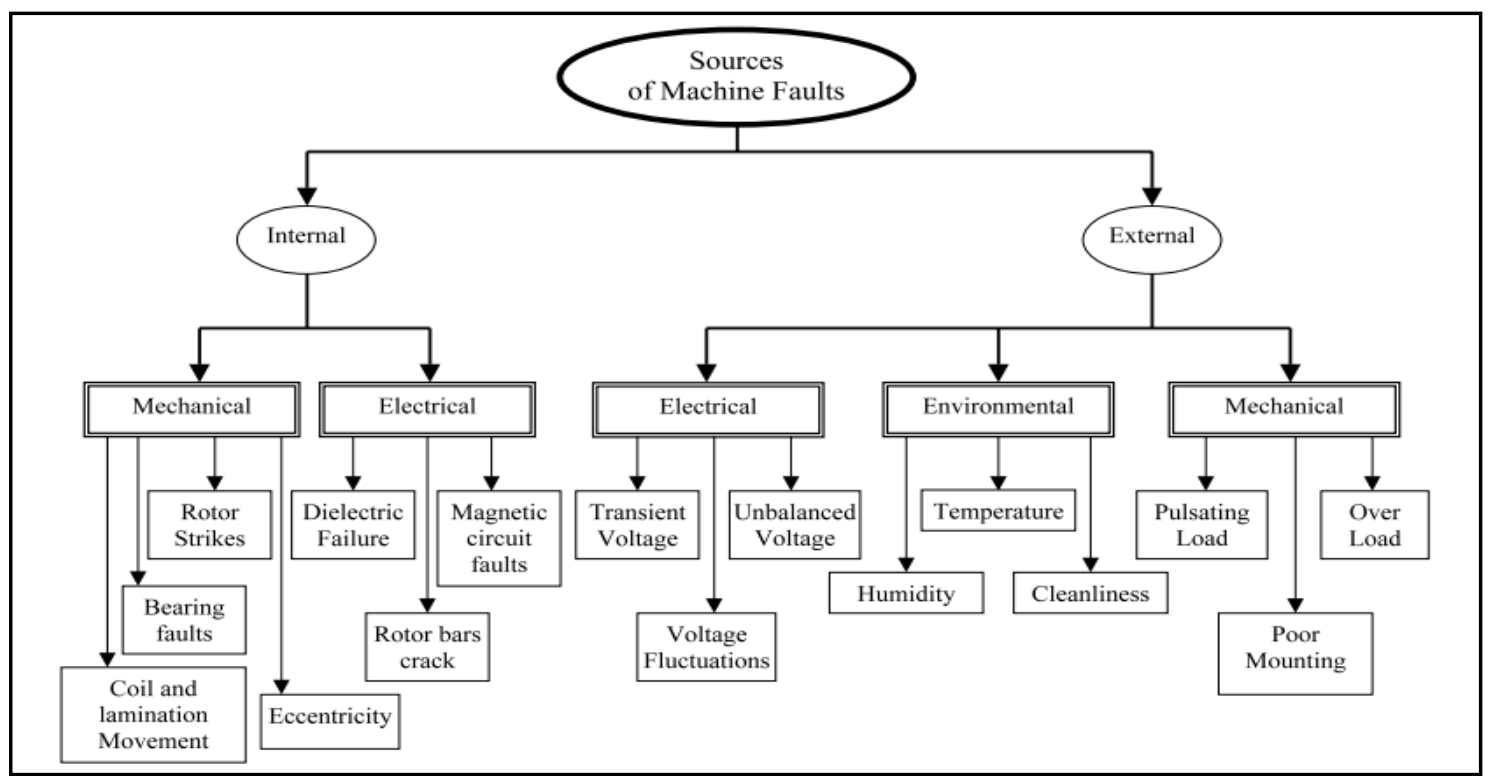

Figure 1. Taxonomy of the faults in the single phase induction motor [26]

Most of the time, the output current and voltage waveforms of inverter devices contain many harmonics, and these harmonics exert harmful effects on motor performance, especially at low speeds [10]. Many developing countries have resorted to using small inverters, especially in home applications, to supply electricity due to interruptions in the power from electrical grids. Home applications use SIMs, fans, water motors and others. From another viewpoint, the weak economic situations in many countries push traders to resort to importing inverters that work with non-standard specifications. As a result, most home devices are badly damaged when they are supplied with non-sinusoidal electricity. The present study tested SIM at different loads with power supplied by sinusoidal and non-sinusoidal voltage sources of $220 \mathrm{~V}$ at a frequency of $50 \mathrm{~Hz}$. Power, power factor, total harmonic distortion, vibration and noise were measured to support the experimental results. 


\section{IMPORTANCE OF THIS STUDY}

Though numerous modern devices are used for fault diagnosis of induction motors in laboratories across the globe, the researchers have failed to address the gaps noted in the earlier studies. In this study, the researcher has carried out a detailed investigation into the effect of these faults. He also focused on the impact of the non-sinusoidal power supplies on the performance of the SIMs, under varying load conditions and objectives. The results of the study would allow the engineering designer to understand the different faults and their effect on motor performance. This study has attempted to contribute to the knowledge by focusing on 4 main issues, i) relationship between the input currents having various faults under different operation loads, ii) effect of these faults on the total harmonic distortion (THD) values for the current and voltage under different operating loads, iii) the effect of the vibration and power factor (PF) generated by the motor during its operation using different loads, and iv) effect of the capacitor-run value on the motor operating under different faults.

\section{DESCRIPTION OF SINGLE PHASE INDUCTION MOTOR}

Inductive motors are the most widely used electric machines in industries due to their robust installation, low cost and high reliability. These machines can also operate from a horsepower level to very high capacity [36]. Therefore, their maintenance must be given due attention to avoid faults. Studies on the control of electric motors have been increasing recently. New research and discoveries in universities and industries have provided tools for predicting and monitoring motor conditions. Many devices and systems have been developed and used extensively in relevant industries and transport. Figure 2 shows different parts of the SIM structure.

In SIM, the auxiliary files remain with the main files during the continuous operation of the motor. Motor installation can be simplified by removing the centrifugal switch referred to in the two previous cases. Figure 3 shows the connection of SIM's main and auxiliary windings. The design of the auxiliary files and capacitor is based on continuous operation; thus, the motor is equivalent to a perfect two-stage, full-load motor in which no reverse field exists, leading to improved efficiency and elimination of noise caused by the reverse field. The result is a quiet motor during operation, and a permanent capacitor is adopted to improve the power factor during operation. This type of motor is utilised in applications that require minimal sound during operation.

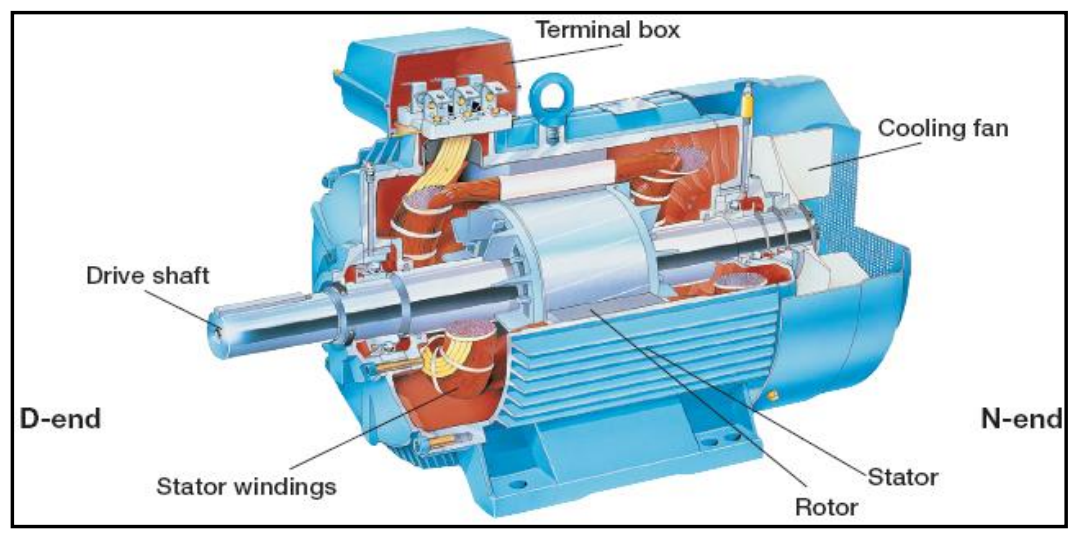

Figure 2. Structure of SIM

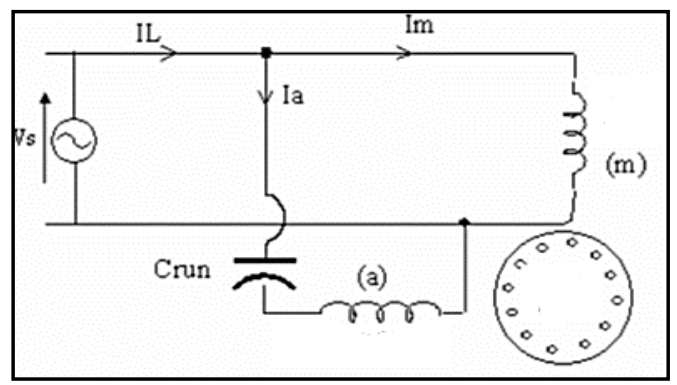

Figure 3. The diagram of SIM [36] 


\section{METHOD}

In this work, practical tests were conducted on SIM. The experimental work of this paper was completed in the power and electrical machines laboratories of the main office of the Department of Electrical Engineering, University of Mosul, Iraq. The rated work values of single phase induction motor which have been used in this work is $0.5 \mathrm{HP}, 50 \mathrm{~Hz}$, and 220 Volts. Figure 4 shown this motor with all divices that used in the exprimental tests. The instruments listed below were used to collect the data:

- Smart oscilloscope, type OWON SDS 9302.

- Power digital meter, type AEMC Model 8220.

- Current sensor.

- Voltage source with a sine wave.

- Voltage source that is non-sinusoidal.

For validation, the study's results were compared with real data from the motor factory. Table 2 shows the characteristics of the motor.

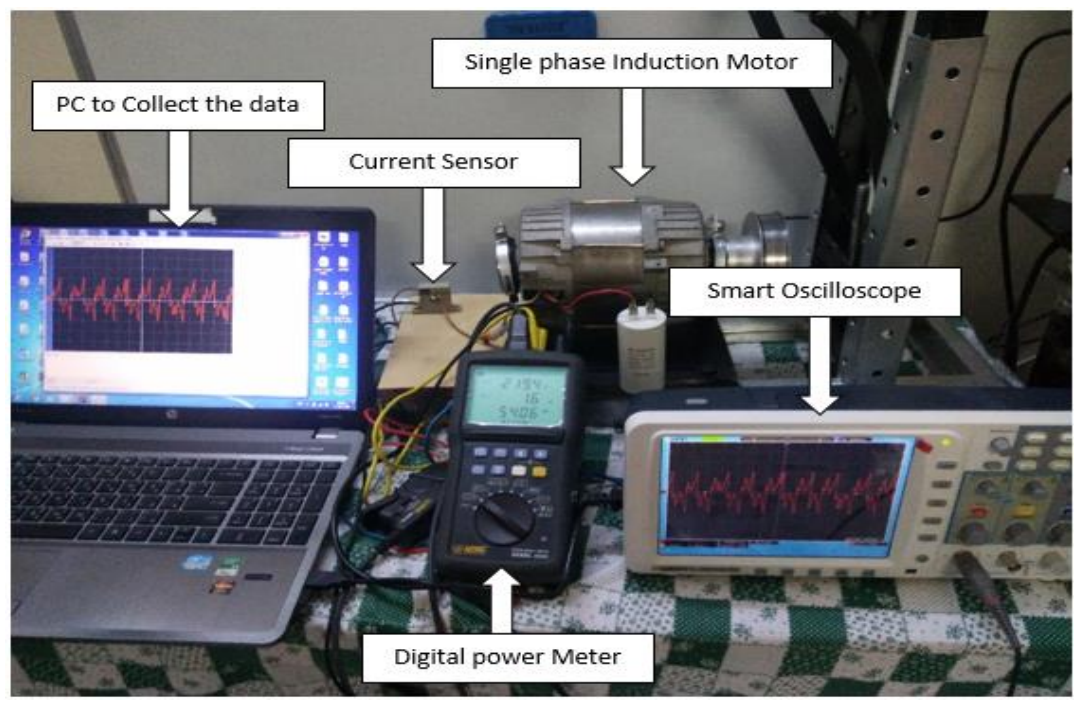

Figure 4. The experimental setup to collect the data

Table 2. Characteristics of single phase induction motor

\begin{tabular}{cc}
\hline Name & Value \\
\hline $\mathrm{V}$ & 220 \\
$\mathrm{~Hz}$ & 50 \\
$\mathrm{HP}$ & $1 / 2$ \\
$\mathrm{PH}$ & 1 \\
$\mathrm{AMP}$ & 3 \\
$\mathrm{RPM}$ & 1425 \\
$\mathrm{AMB}$ & $40^{\circ} \mathrm{C}$ \\
$\mathrm{CAP}$ & $16 \mu \mathrm{F}$ \\
\hline
\end{tabular}

The current waveform of SIM was determined by using the current sensor at different loads and operating amplitudes. The current waveform was drawn using the oscilloscope, as shown in Figure 3. One of the known important readings is the value of input current from the source (sinusoidal and non-sinusoidal). The digital power device, shown in Figure 3, was used to determine the value of input current, power and power factor.

In addition, the vibration value of SIM was measured at different loads, different amplitudes and at each type of source (sinusoidal and non-sinusoidal). Mechanical load was used to obtain rated current and $70 \%$ of rated current for comparison. The results were read by measurements in the case of operating a SIM from a sinusoidal or non-sinusoidal source. The measurements were performed at standard conditions of $23{ }^{\circ} \mathrm{C}$ temperature, $39 \%$ humidity and 1016 mbar atmospheric pressure. The results obtained will be discussed in detail in the results section. Figure 5 shows the voltage wave of the sinusoidal power supply in which the motor was operated, and Figure 6 shows the voltage wave of a non-sinusoidal source that is commonly used in shops and homes during power outages. 


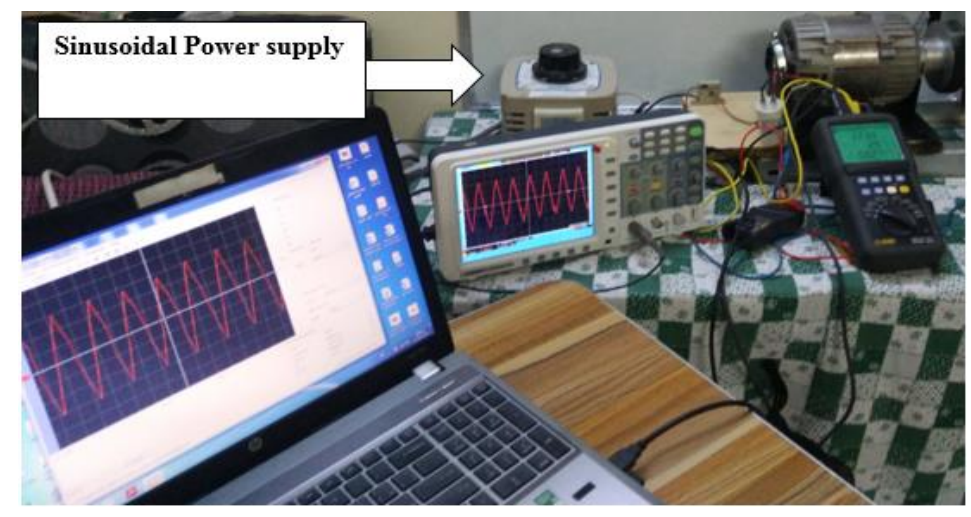

Figure 5. Sinusoidal power supply

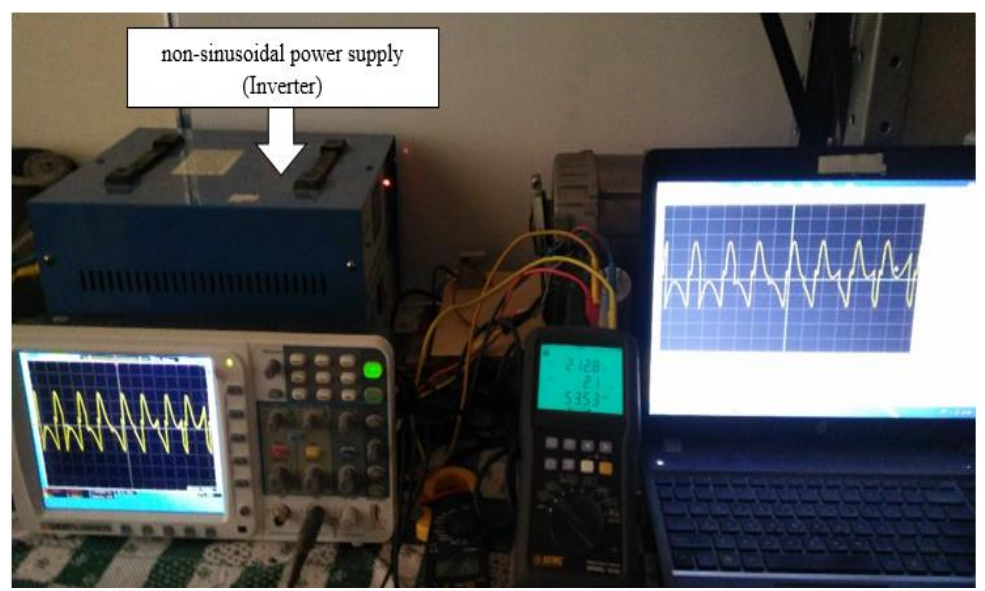

Figure 6. Non-sinusoidal power supply

\section{RESULTS AND DISCUSSION}

The results of this study are presented in 5 different parts. Part 1 described the current of the motor that was operated using the sinusoidal and non-sinusoidal power sources. Figure 7 indicates that the input current increased by $>6 \%$ if the motor was operated using a non-sinusoidal power supply. An obvious effect was noted when the researchers used the non-sinusoidal power supply for operating the motor on the current value; and when it was withdrawn from the power source. As the non-sinusoidal waveform showed a significant distortion, it generated large and numerous harmonics within the motor. Hence, a higher current is used for operating this motor.

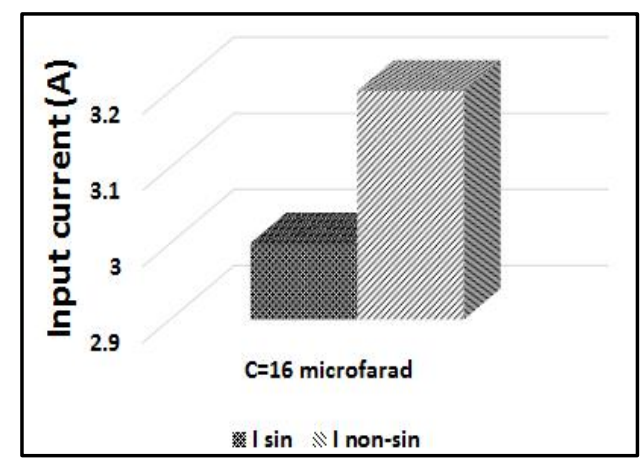

Figure 7. Input current with different power supply at $100 \%$ full load 
In this study, the researcher determined the effect of the load on the SIM performance. For this purpose, they considered different load values while operating the motor using a non-sinusoidal source. The current values were measured under different load cases, i.e., full load, zero loads and $70 \%$ load. As shown in Figures 8(a) and (b), the current indicated value when the motor was not loaded and operated using the sinusoidal power supply. On the other hand, the no-load current value is shown when the motor was operated using a non-sinusoidal power source.

All current signals were obtained through the current sensor, and these signals were inputted into a computer. Which is used to determine the shape of the current and the amount of change that occurred when a non-sinusoidal or sinusoidal power supply was used. Figures 9(a) and (b) shows the current waves at full load as the motor operated using different power supplies.

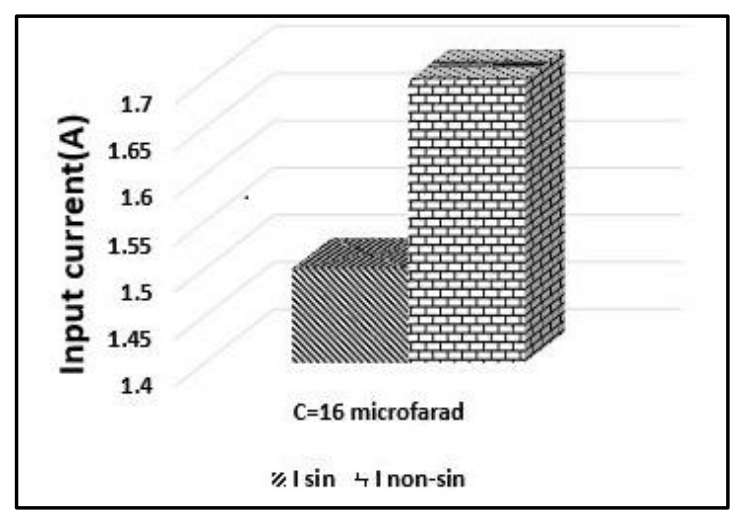

(a)

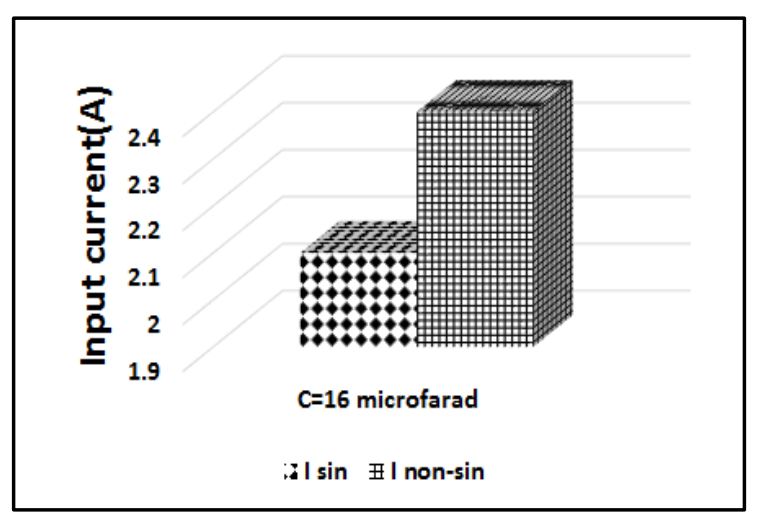

(b)

Figure 8. Input current with different power supply: (a) no-load current and (b) $70 \%$ full load current
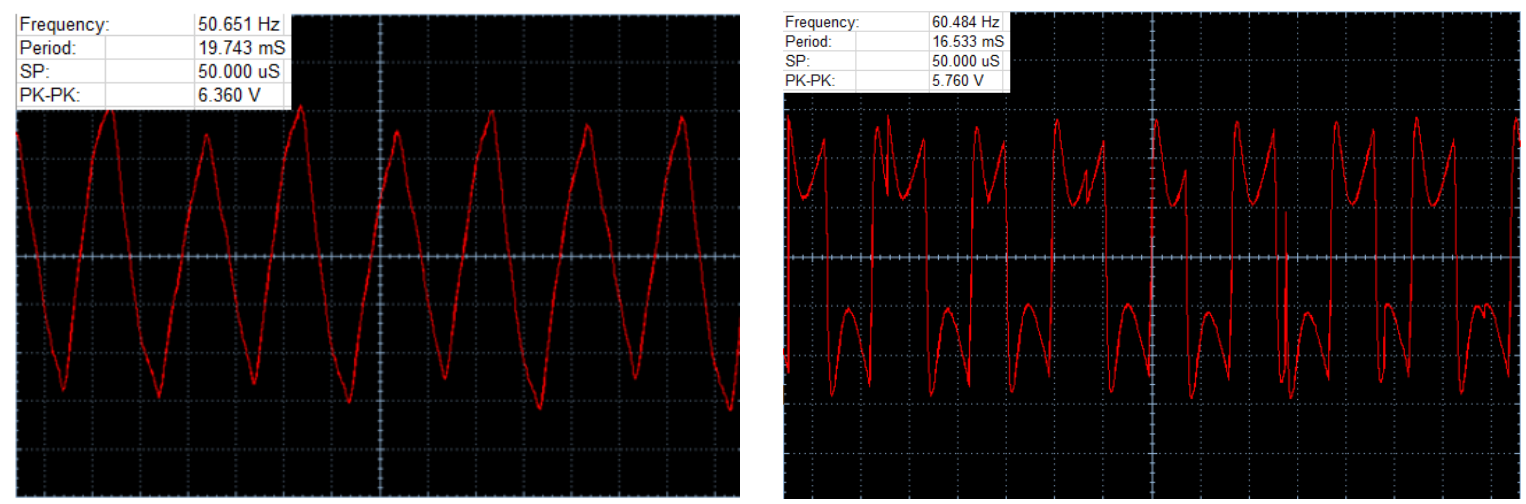

(a)
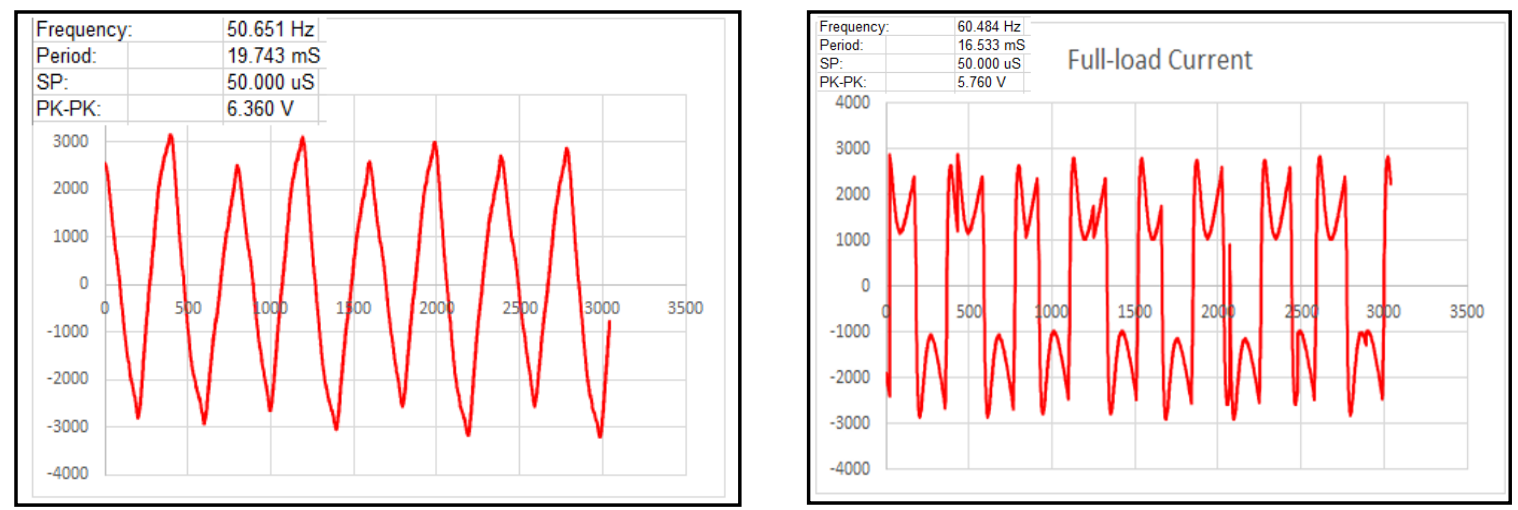

(b)

Figure 9. Current waves in the: (a) smart oscilloscope, type OWON SDS 9302 and (b) current sensor 
The modern type of plotter (Owen) used and a sensor for accurately plotting the results. A difference current from was noted in the waveforms when the motor was operated using different power supply sources. The difference in the shape was attributed to different factors, i.e., the effect of the harmonics on the sensor activity and the effect of the harmonics on the operation of the electronic circuits within the plotter.

It is important to determine the optimal value of the capacitor that was used in the SIM since it significantly affects the noise, vibrations and parasitic torques if an improperly-run capacitor was used in the machine. It is also essential to select a proper value of the capacitor. Figure 10 highlights the effect of altering the running capacitor values on the performance of the machine when different power sources were used for supplying the current.

The impact of the effect of the capacitor value on the performance of the motors that were supplied by the sinusoidal or non-sinusoidal power sources was determined. By, selected many different values from the capacitor along with varying loads for determining this effect. As shown in the Figure10, indicated the value of the input current for the motor that was powered by a sinusoidal source. On the other hand, the input current value for the SIM that was powered using a non-sinusoidal source was displayed.
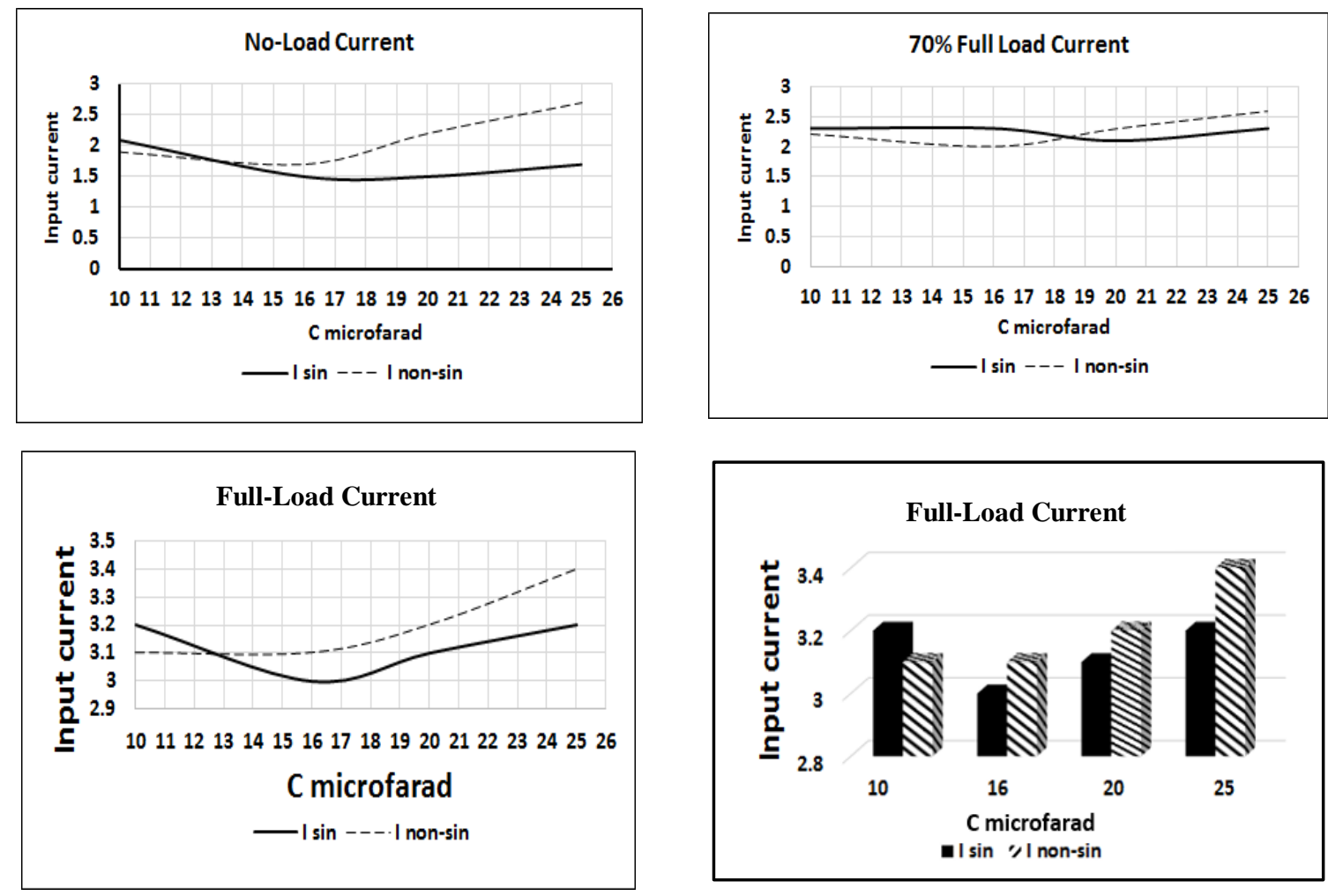

Figure 10. Different values, input current, loads with different values of running capacitor

Power factor (PF) played a vital role in the AC circuits based on the load. If a large current is supplied at a smaller PF value, it could lead to a significantly high voltage loss in the alternator and the transmission lines. This would further decrease the load handling capacity of the system. Hence, it is necessary to improve the PF for maximising the current-carrying capacity, improving the voltage transmitted to the appliance, decrease power losses and reduce electricity bills. Hence, the researchers regarded the PF in part 2 of the results presented in the study. Figure 11 described the PF value that was generated under varying capacitors and loads. The power factor is considered the second category of the results. Figure 11 displays the power factor under different loads and capacitors. Mechanical load was used in this work to load the motor, as indicated in Figure 12. shows the input power for the motor when it is supplied by sinusoidal and non-sinusoidal power. 

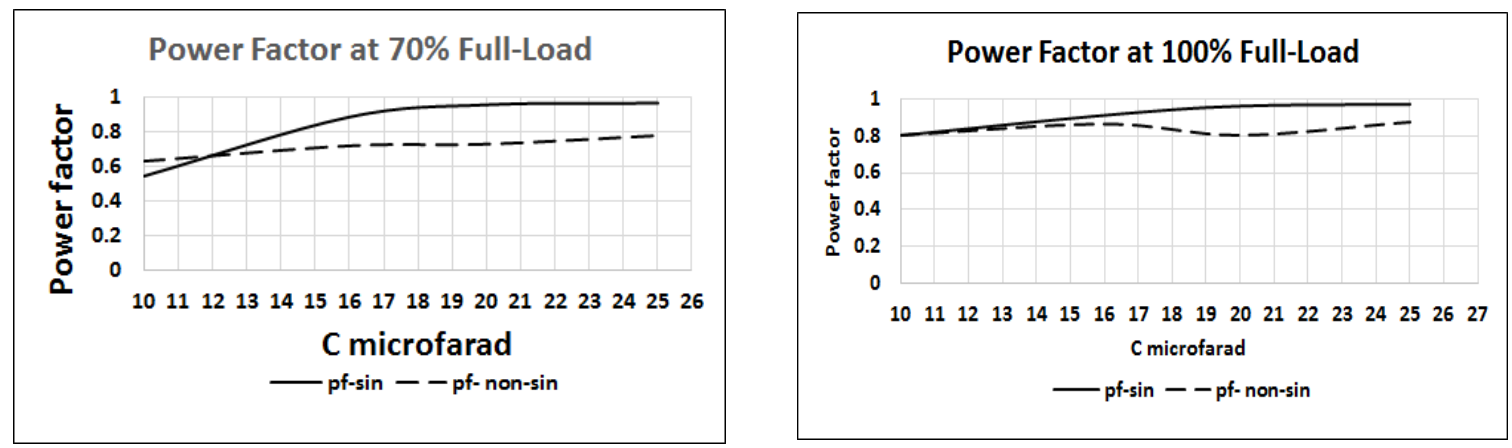

Figure 11. Power factor with different loads
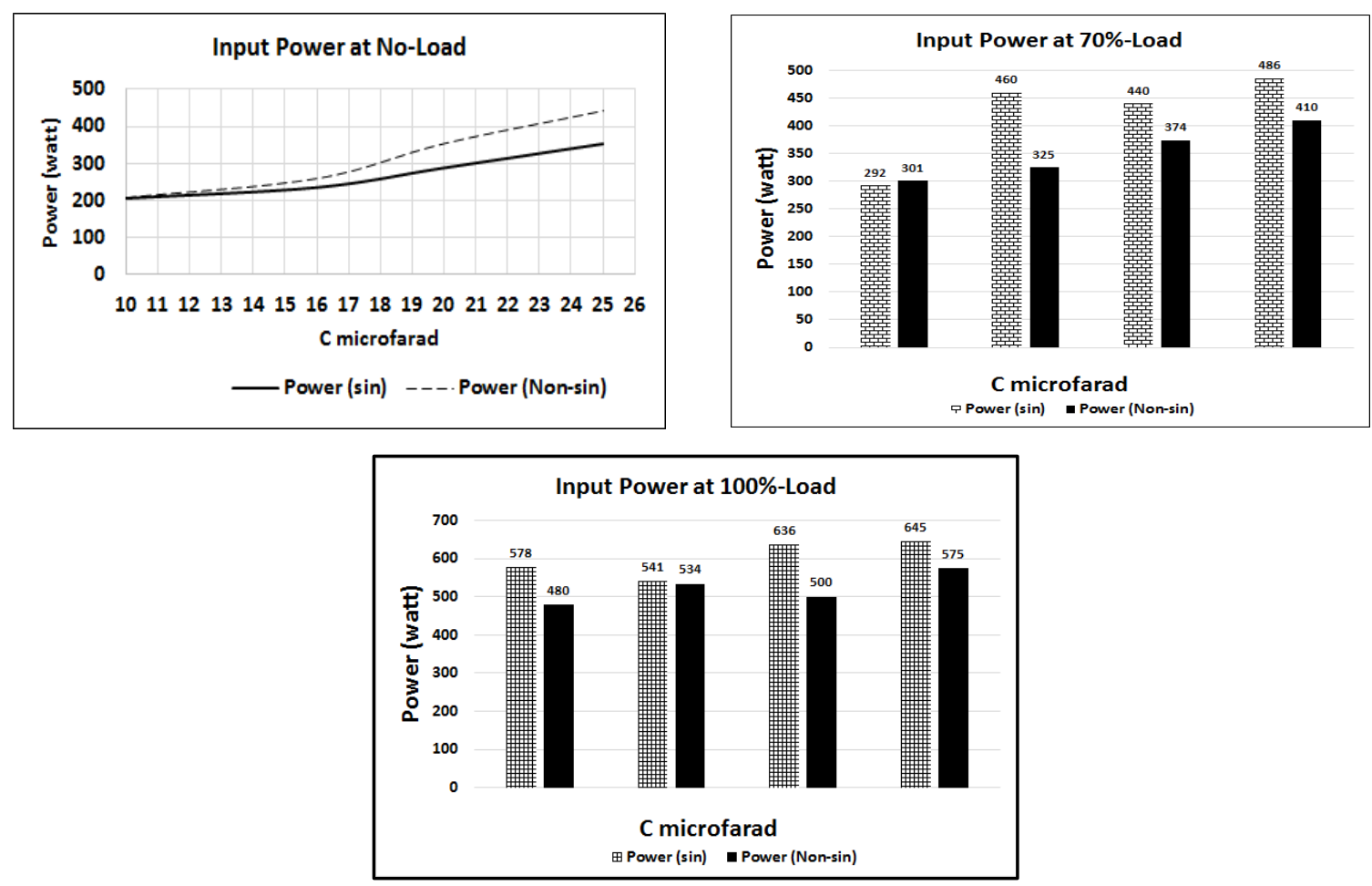

Figure 12. Input power with different loads and running capacitors

Additionally, THD was another important parameter that affected the power systems and it needs to be set as low as possible. A low THD in the power systems indicates a high PF, low peak currents and better efficiency. The nature of the load determines the properties of the current, and thus the PF. For determining the parameter that caused differences in the harmonic currents, the researchers investigated the harmonic nature of the current waveforms in part 3 .

In this study, the investigation of the harmonics originating from the power source was done. Thus, part 4 of the results highlighted the effect of the power source quality on the THD of the currents. They assessed the effect of the harmonics on the PF, input power, shape of input current, properties of the motor and its performance, as shown in Figures 13 and 14.

Any unwanted distortion increases the current in the power systems that then increases the temperature in the neutral conductors and the distribution transformers. High-frequency harmonics lead to further core loss in the motors that results in the excessive heating of the core. Any vibration damages the electric motor in different ways. Firstly, it accelerates the bearing failure as it leads to indentations on the bearing raceways near the spacer or ball spacing's. Secondly, it could also loosen the windings and mechanically damage the insulation by flaking, fracturing or eroding the insulating material.

The vibration caused in the motor when the motor was supplied with the sinusoidal or nonsinusoidal power supplies. Also noted that if they supplied the non-sinusoidal power to the vehicle, it 
increased the harmonics, which was reflected in its properties and performance. For demonstrating this effect, the described results of the vibration that was independent of noise (will be discussed in a future study). Figure 15 presents the vibration of the SIM at a full load current. This figure highlighted the vibration of the SIM when the motor was supplied with a sinusoidal and a non-sinusoidal power supply, and it was completely loaded. Finally, the researchers also determined the effect of the non-sinusoidal power supply on the SIM vibrations. Different values of running capacitors were also presented to show the effect of these values on motor performance when the motor is operating with different power supplies, as shown in Figure 16.

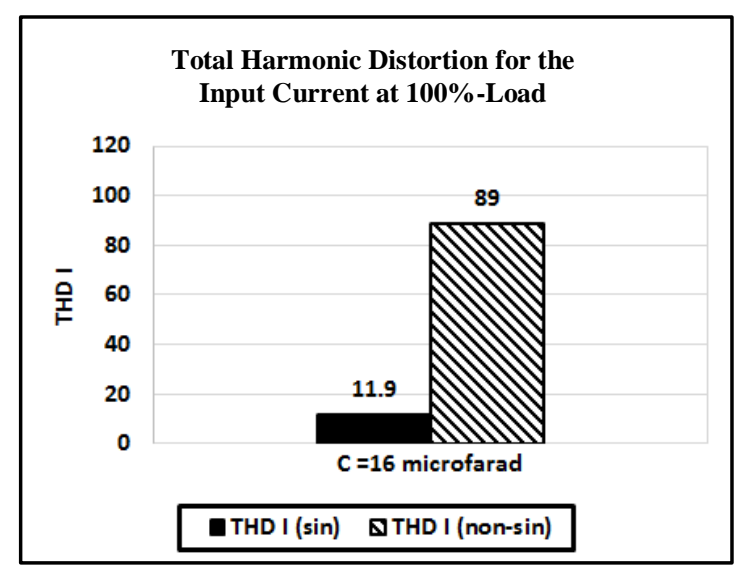

Figure 13. THD of the current with the different power supplies
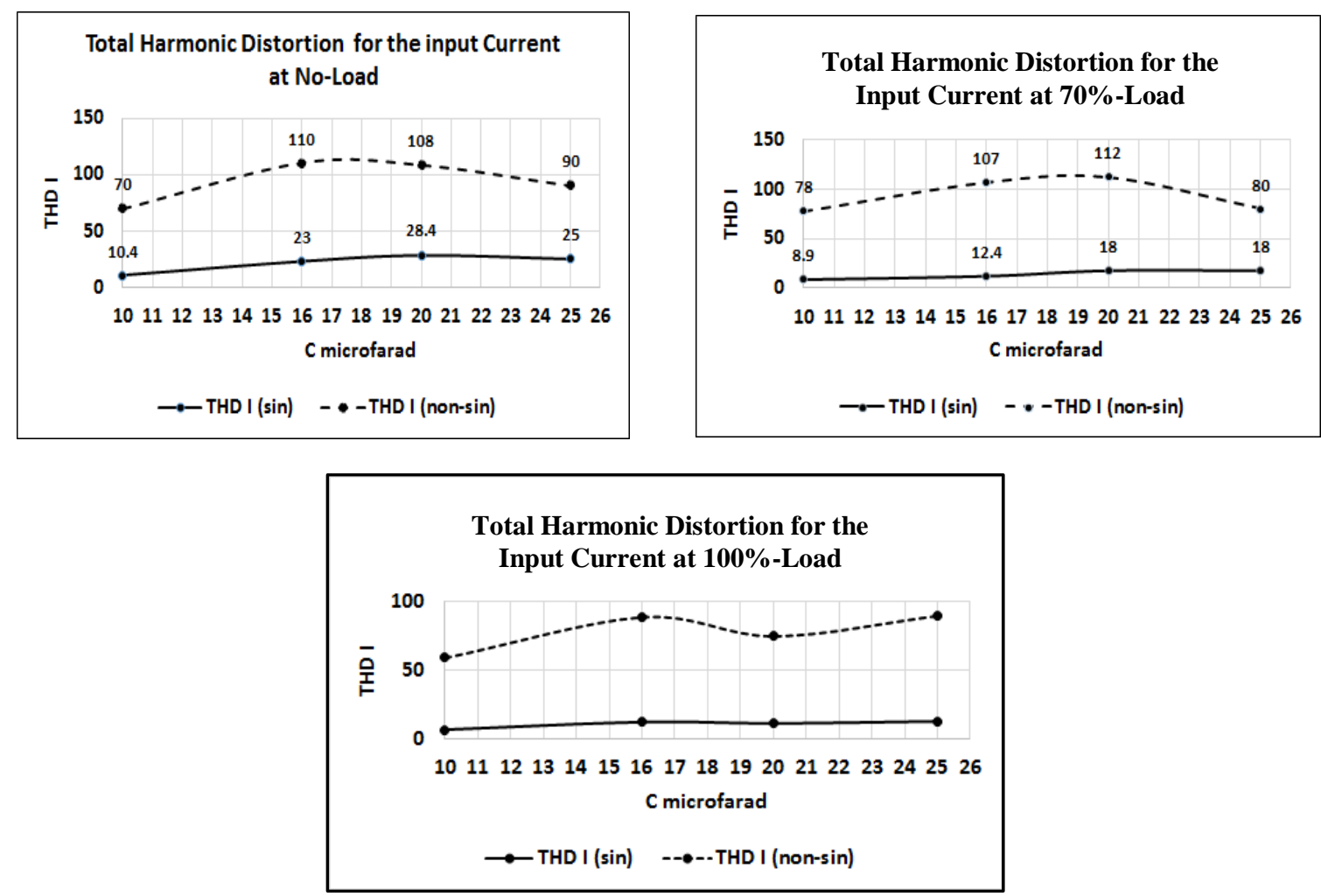

Figure 14. THD of the current with the different power supplies at the different loads 


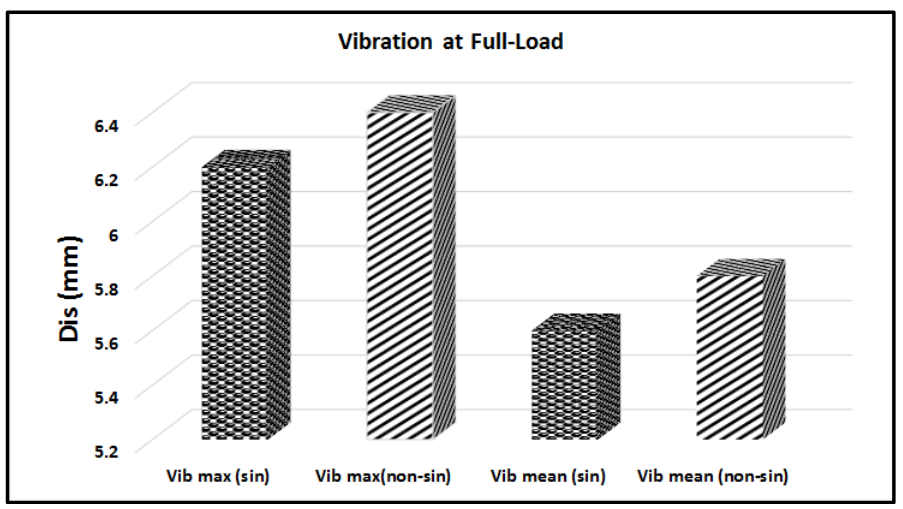

Figure 15. The vibration of the motor when works from different power supplies
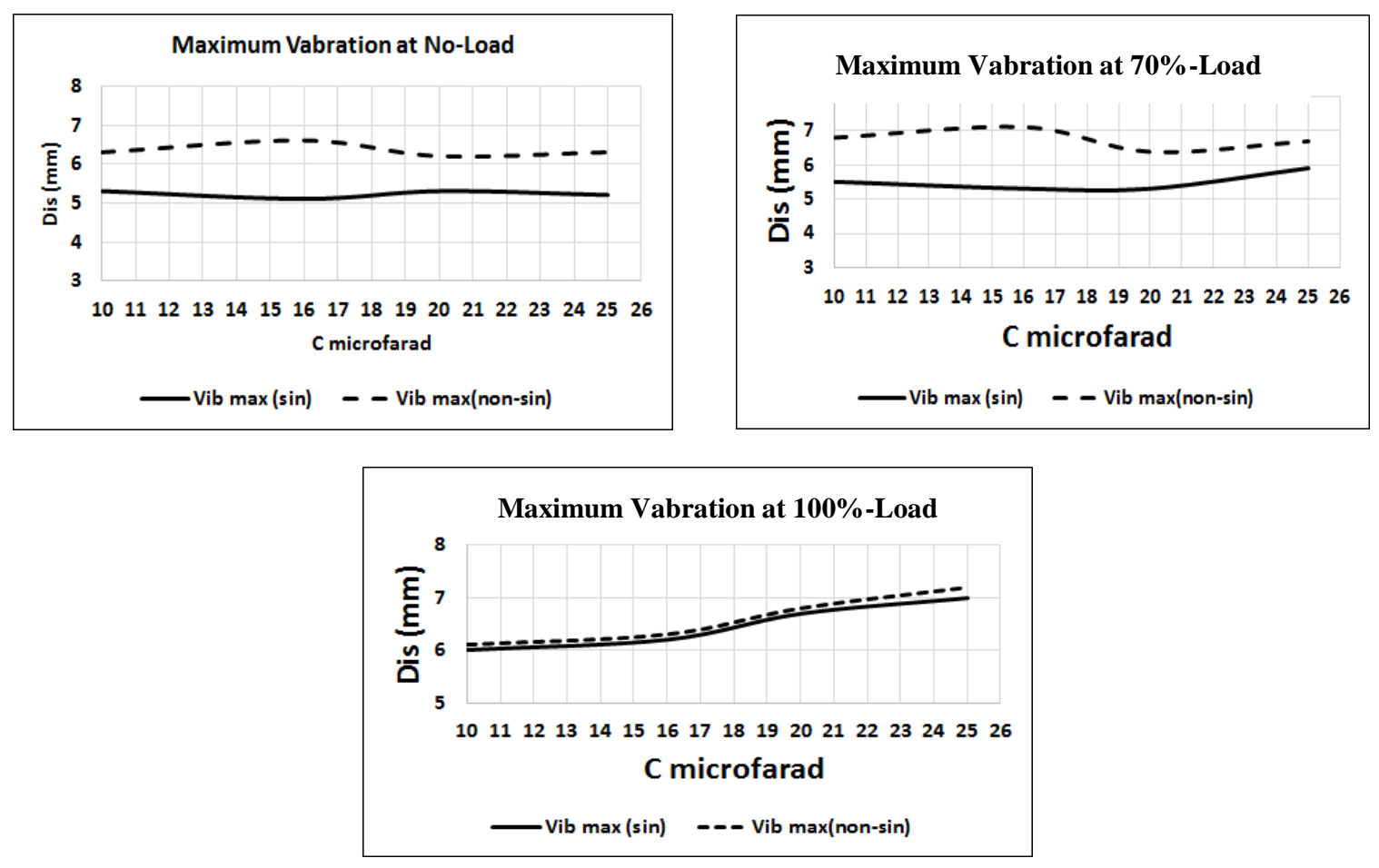

Figure 16. The vibration of motor in different values of running capacitor with different supplies

\section{CONCLUSION}

In this paper, determined the effect of the non-sinusoidal power supply on the properties and performance of the SIM. A larger value was noted if the motor was supplied with a non-sinusoidal power supply. In this study, the researchers noted the harmonic generator factor and its effect on the performance of the induction motor. Their results indicated that the SIMs required a higher current when it was supplied with the non-sinusoidal source. A significant difference was noted with regards to the power value that was absorbed from the source between the 2 different power supplies. Noted that the PF was ideal if the motor was powered with the sinusoidal power source. The current load increased to $89 \%$ (i.e., an $11 \%$ increase) if the motor was operated using a sinusoidal source than the non-sinusoidal source. These results were further validated and compared to the experimental data supplied by the manufacturer. The technique used in this study was cost-effective and could allow many researchers to detect the issues that arose if they powered an induction motor with a non-sinusoidal power source. Furthermore, this study could also help the designers establish an appropriate solution for the SIMs that were operated with the non-sinusoidal power supply. 


\section{ACKNOWLEDGEMENTS}

The author would like to thank the Mosul University, College of Engineering, Electrical

Department, for the support given during this work.

\section{REFERENCES}

[1] D. A. B. Al Nemaa and O. S. Yaheya, "Performance Analysis of a Single Phase Induction Motor For Different Values of Running Capacitor Abstract," Tikrit Journal of Engineering Sciences, vol. 18, no. 1, pp. 19-27, 2011.

[2] K. Makowski and M. J. Wilk, "Experimental verification of field-circuit model of a single-phase capacitor induction motor," Przeglad Elektrotechniczny, vol. 88. no. 7b, pp. 116-118, 2012.

[3] B. Tekgun, Y. Sozer, and I. Tsukerman, "Modeling and parameter estimation of split - Single phase induction motors," 2014 IEEE Energy Conversion Congress and Exposition (ECCE), 2014, pp. 1317-1324, doi: 10.1109/ECCE.2014.6953553.

[4] K. Makowski and M. J. Wilk, "Determination of dynamic characteristics of the single-phase capacitor induction motor," Przeglad Elektrotechniczny, vol. 87. no. 5, pp. 231-237, 2012.

[5] A. Glowacz and Z. Glowacz, "Diagnosis of stator faults of the single-phase induction motor using acoustic signals," Applied Acoustics, vol. 117, pp. 20-27, 2017, doi: 10.1016/j.apacoust.2016.10.012.

[6] B. S. Diboma and T. T. Tatietse, "Power interruption costs to industries in Cameroon," Energy Policy, vol. 62, pp. 582-592, 2013, doi: 10.1016/j.enpol.2013.07.014.

[7] P. Linares and L. Rey, "The costs of electricity interruptions in Spain: Are we sending the right signals?," Energy Policy, vol. 61, pp. 751-760, 2013, doi: 10.1016/j.enpol.2013.05.083.

[8] M. Chirindo, M. A. Khan, and P. S. Barendse, "Considerations for Nonintrusive Efficiency Estimation of Inverter-Fed Induction Motors," in IEEE Transactions on Industrial Electronics, vol. 63, no. 2, pp. 741-749, Feb. 2016, doi: 10.1109/TIE.2015.2477801.

[9] V. S. Santos, P. R. V. Felipe, J. R. G. Sarduy, N. A. Lemozy, A. Jurado, and E. C. Quispe, "Procedure for Determining Induction Motor Efficiency Working Under Distorted Grid Voltages," in IEEE Transactions on Energy Conversion, vol. 30, no. 1, pp. 331-339, March 2015, doi: 10.1109/TEC.2014.2335994.

[10] G. K. Singh, "A research survey of induction motor operation with non-sinusoidal supply wave forms," Electric Power Systems Research, vol. 75, no. 2-3, pp. 200-213, 2005, doi: 10.1016/j.epsr.2005.04.001.

[11] P. Orsag, S. Kocman, and L. Paulinsky, "Efficiency determination of inverter-fed induction motor for low power applications," Przeglad Elektrotechniczny, vol. 88, no. 10A, pp. 305-307, 2012.

[12] A. H. Rajaei, M. Mohamadian, S. M. Dehghan, and A. Yazdian, "Single-phase induction motor drive system using z-source inverter," IET Electric Power Applications, vol. 4, no. 1, pp. 17-25, 2010, doi: 10.1049/iet-epa.2008.0304.

[13] R. K. Bhukya and P. S. Kumar, "Simplified down sampling factor based modified SVPWM technique for cascaded inverter fed induction motor drive," International Journal of Advances in Applied Sciences, vol. 9, no. 1, pp. 20-26, 2020, doi: 10.11591/ijaas.v9.i1.pp20-26.

[14] D. López-Pérez and J. Antonino-Daviu, "Application of Infrared Thermography to Failure Detection in Industrial Induction Motors: Case Stories," in IEEE Transactions on Industry Applications, vol. 53, no. 3, pp. 1901-1908, May-June 2017, doi: 10.1109/TIA.2017.2655008.

[15] B. Van Hecke, J. Yoon, and D. He, "Low speed bearing fault diagnosis using acoustic emission sensors," Applied Acoustics, vol. 105, pp. 35-44, 2016, doi: 10.1016/j.apacoust.2015.10.028

[16] D. H. Hwang, Y. W. Youn, J. H. Sun, K. H. Choi, J. H. Lee, and Y. H. Kim, "Support vector machine based bearing fault diagnosis for induction motors using vibration signals," Journal of Electrical Engineering and Technology, vol. 10, no. 4, pp. 1558-1565, 2015, doi: 10.5370/JEET.2015.10.4.1558.

[17] S. Zhang, S. Lu, Q. He, and F. Kong, "Time-varying singular value decomposition for periodic transient identification in bearing fault diagnosis," Journal of Sound and Vibration, vol. 379, pp. 213-231, 2016, doi: 10.1016/j.jsv.2016.05.035.

[18] X. Yan, M. Jia, and L. Xiang, "Compound fault diagnosis of rotating machinery based on OVMD and a 1.5-dimension envelope spectrum," Measurement Science and Technology, vol. 27, no. 7, 2016, doi: 10.1088/0957-0233/27/7/075002.

[19] Z. X. Yang and J. H. Zhong, "A hybrid EEMD-based SampEn and SVD for acoustic signal processing and fault diagnosis," Entropy, vol. 18, no. 4, 2016, doi: 10.3390/e18040112.

[20] J. Józwik, "Identification and Monitoring of Noise Sources of Cnc Machine Tools By Acoustic Holography Methods," Advances in Science and Technology Research Journal, vol. 10, no. 30, pp. 127-137, 2016, doi: 10.12913/22998624/63386.

[21] M. A. Al-Yoonus and O. S. Al-Deen Alyozbaky, "Detection of internal and external faults of single-phase induction motor using current signature," International Journal of Electrical and Computer Engineering, vol. 11, no. 4, pp. 2830-2841, 2021, doi: 10.11591/ijece.v11i4.pp2830-2841.

[22] A. Siddique, G. S. Yadava, and B. Singh, "A review of stator fault monitoring techniques of induction motors," in IEEE Transactions on Energy Conversion, vol. 20, no. 1, pp. 106-114, March 2005, doi: 10.1109/TEC.2004.837304.

[23] Y. Zhongming and W. Bin, "A review on induction motor online fault diagnosis," Proceedings IPEMC 2000. Third International Power Electronics and Motion Control Conference (IEEE Cat. No.00EX435), vol. 3, 2000, pp. 1353-1358, doi: 10.1109/IPEMC.2000.883050

[24] T. Kerdphol, Y. Qudaih, and Y. Mitani, "Optimum battery energy storage system using PSO considering dynamic demand response for microgrids," International Journal of Electrical Power \& Energy Systems, vol. 83, pp. 58-66, 2016, doi: 10.1016/j.jiepes.2016.03.064.

[25] R. Waswani, A. Pawar, M. Deore, and R. Patel, "Induction motor fault detection, protection and speed control using arduino," 2017 International Conference on Innovations in Information, Embedded and Communication Systems (ICIIECS), 2017, pp. 1-5, doi: 10.1109/ICIIECS.2017.8276071

[26] S. A. S. Al Kazzaz and G. K. Singh, "Experimental investigations on induction machine condition monitoring and fault diagnosis using digital signal processing techniques," Electric Power Systems Research, vol. 65, no. 3, pp. 197-221, 2003, doi: 10.1016/S0378-7796(02)00227-4.

[27] C. Da Costa, M. Kashiwagi, and M. H. Mathias, "Rotor failure detection of induction motors by wavelet transform and Fourier transform in non-stationary condition," Case Studies in Mechanical Systems and Signal Processing, vol. 1, pp. 15-26, 2015, doi: 10.1016/j.csmssp.2015.05.001.

[28] M. Gutten et al., "Maintenance diagnostics of transformers considering the influence of short-circuit currents during operation," Eksploatacja i Niezawodność, vol. 19, no. 3, pp. 459-466, 2017, doi: 10.17531/ein.2017.3.17. 
[29] S. Adamczak, K. Stẹpień, and M. Wrzochal, "Comparative Study of Measurement Systems Used to Evaluate Vibrations of Rolling Bearings," Procedia Engineering, vol. 192, pp. 971-975, 2017, doi: 10.1016/j.proeng.2017.06.167.

[30] J. Hang, J. Zhang, and M. Cheng, "Application of multi-class fuzzy support vector machine classifier for fault diagnosis of wind turbine,” Fuzzy Sets and Systems, vol. 297, pp. 128-140, 2016, doi: 10.1016/j.fss.2015.07.005.

[31] P. A. Delgado-Arredondo et al., "Comparative Study of Time-Frequency Decomposition Techniques for Fault Detection in Induction Motors Using Vibration Analysis during Startup Transient," Shock and Vibration, 2015, doi: 10.1155/2015/708034.

[32] W. Sawczuk and G. M. Szymański, "Diagnostics of the railway friction disc brake based on the analysis of the vibration signals in terms of resonant frequency," Archive of Applied Mechanics, vol. 87, no. 5, pp. 801-815, 2017, doi: 10.1007/s00419-016-1202-0.

[33] A. Glowacz, "Fault diagnostics of acoustic signals of loaded synchronous motor using SMOFS-25-EXPANDED and selected classifiers in Bosnian Dijagnostika greške akustičkih signala opterecenog sinkronog motora primjenom SMOFS-25-EXPANDED i odabranih klasifikatora," Tehnički vjesnik, vol. 23, no. 5, pp. 1365-1372, 2016, doi: 10.17559/TV-20150328135652.

[34] W. Caesarendra, B. Kosasih, A. K. Tieu, H. Zhu, C. A. S. Moodie, and Q. Zhu, "Acoustic emission-based condition monitoring methods: Review and application for low speed slew bearing," Mechanical Systems and Signal Processing, vol. 72-73, pp. 134-159, 2016, doi: 10.1016/j.ymssp.2015.10.020.

[35] E. P. Frigieri, P. H. S. Campos, A. P. Paiva, P. P. Balestrassi, J. R. Ferreira, and C. A. Ynoguti, "A mel-frequency cepstral coefficient-based approach for surface roughness diagnosis in hard turning using acoustic signals and gaussian mixture models," Applied Acoustics, vol. 113, pp. 230-237, 2016, doi: 10.1016/j.apacoust.2016.06.027.

[36] O. S. Alyozbaky, "Parasitic Torques of single phase induction motors and its effect on the generated noise and vibration," AlRafidain Engineering Journal, vol. 20, no. 2, pp. 9-18, 2012.

\section{BIOGRAPHIES OF AUTHORS}
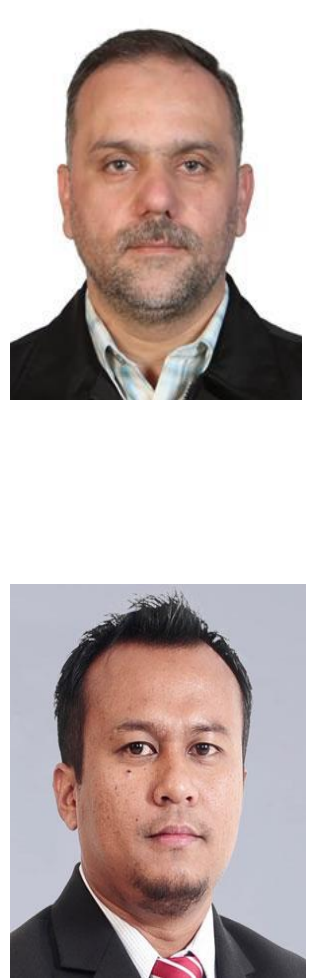

Omar Sharaf Al-deen Alyozbaky (iD 8 SC P He obtained his Bachelor of Science (BSc) in Electrical Engineering in 2001 from the Electrical Engineering Department, College of Engineering, University of Mosul, Iraq. Then he was appointed as an assistant engineer in the same mentioned department. After that, he got MSc in "Overcome the effect of Critical distance in XLPE High Voltage Cables by inductive shunt compensator ", 2008 from the same mentioned department as well. Upon his graduation, he was appointed as teaching staff (assistant lecturer) in the Electrical Engineering Department, College of Engineering, University of Mosul. In 2012, he obtained the scientific title (lecturer) and the Ph.D. degree in the Department of Electrical and Electronic Engineering, Faculty of Engineering, University Putra Malaysia in 2017. Since 2014, he was a member of the Centre for Electromagnetic and lightning protection research (CELP). Now, he is Assistant Professor Electrical Engineering Department, College of Engineering, University of Mosul. The subjects for interest, Renewable energy fields associated with the smart grid, thermal modeling transformer design, and electrical machines. He can be contacted at email: O.SH.Alyozbaky@gmail.com and o.yehya@uomosul.edu.iq.

Mohd Zainal Abidin Ab-Kadir (iD 8 SC P He graduated with B.Eng. degree in Electrical and Electronic from Universiti Putra Malaysia and obtained his PhD from the University of Manchester, United Kingdom in High Voltage Engineering. Currently, he is a Professor in the Department of Electrical and Electronics Engineering, Faculty of Engineering, Universiti Putra Malaysia. To date he has authored and coauthored over 300 research papers. His research interests include high voltage engineering, insulation coordination, lightning protection, EMC/EMI, kerauna-medicine and power system transients. Prof Zainal is a Professional Engineer (PEng) and a Chartered Engineer (CEng), as well as member of IEM, IET, CIGRE and Senior Member of IEEE. He is also an IEEE PES Distinguished Lecturer. He can be contacted at email: mzk@upm.edu.my. 